\title{
Suprascapular nerve lesions at the spinoglenoid notch: report of three cases and review of the literature
}

\author{
Jay A Liveson, Michael J Bronson, Michael A Pollack
}

\begin{abstract}
Lesions of the suprascapular nerve can occur at the supraspinatus notch (SSN) or at the spinoglenoid notch (SGN). Electromyographic (EMG), evaluation of the infraspinatus, and especially the supraspinatus muscles distinguishes SGN from SSN lesions. Three cases of SGN lesions, which are more common than SSN lesions, are presented.
\end{abstract}

Entrapment of the suprascapular nerve at the suprascapular notch (SSN) was first described in 1963 by Kopell and Thompson. ${ }^{1}$ No alternative entrapment site was recognised until 1981 when the first case of spinoglenoid notch (SGN) entrapmnt was described by Ganzhorn et $a .^{2}$ Since then nine additional cases of SGN lesions have been published..$^{3-8}$ It is important to distinguish between the SSN and the SGN lesions (fig 1) to avoid surgery to the wrong region. This may be the cause of occasional surgical failure reported before the SGN lesion was recognised. ${ }^{9}$ We present a report of three additional cases of SGN lesions and a review of the literature to define the SGN syndrome.

Case 1

A 22 year old right handed weight lifter noted right shoulder ache which remained unchanged during the previous six months. He did not complain of numbness, or symptoms

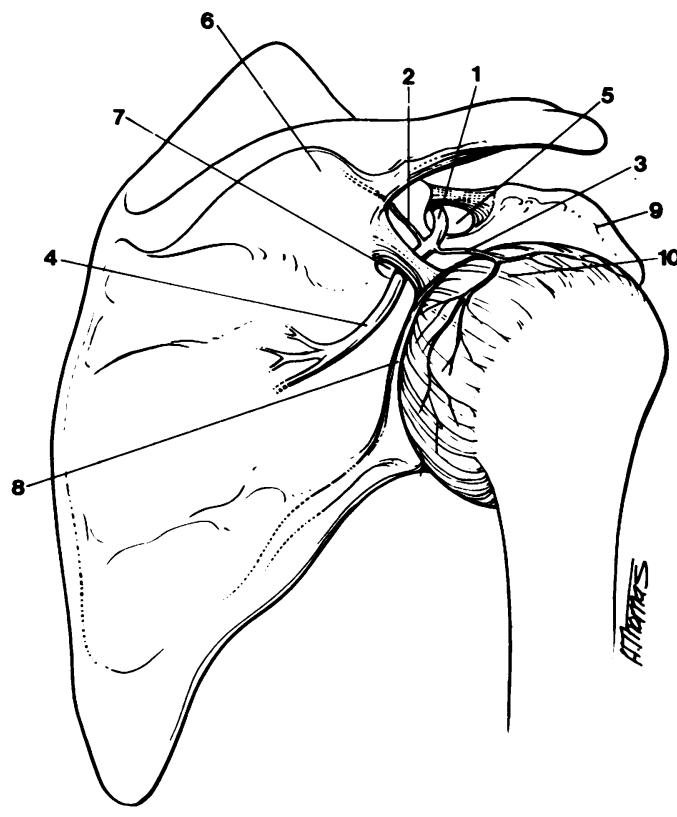

of root involvement (cervical pain, and change from Valsalva's manoeuvre). His past medical history was negative. On physical examination cranial nerves were normal. No weakness was detected on careful manual muscle examination. Sensation was intact. Deep tendon reflexes were active and symmetrical with no pathological reflexes. There was no Horner's sign.

The patient gave up weight lifting and started a programme of physiotherapy. His shoulder ache resolved rapidly, but his muscle bulk did not return to normal for another 12 months. He reported completely normal function.

\section{Case 2}

A 22 year old right handed male was skeet shooting, a month before his examination. $\mathrm{He}$ held the rifle so that the recoil was absorbed by the right shoulder. The following day, he found that he was unable to lift the right shoulder. This gradually subsided but his right scapula appeared to be losing bulk. $\mathrm{He}$ did not complain of numbness or radicular symptoms. His past medical history was negative. On physical examination atrophy was evident in the region of the right infraspinatus with an area of tenderness below the scapular spine. There was no weakness on manual muscle examination, and sensation was intact. Deep tendon reflexes were active and symmetrical with flexor plantar responses. Cranial nerves were normal with no Horner's sign.

The patient was treated conservatively. His strength and scapular muscle bulk increased slowly. After 30 months they were completely normal.

\section{Case 3}

A 25 year old right handed minor league baseball pitcher was alerted by teammates to right scapular atrophy two months before being examined. He was still able to pitch, and denied numbness, and cervical symptoms. There was no precipitating event. His past medical history was negative. On physical examination cranial nerves were normal with no Horner's sign. Atrophy was evident in the right infraspinatus region and external rotation of the right humerus was weak. No other motor or sensory deficit was present. Deep tendon reflexes were active and symmetrical and plantar responses were flexor.

After a temporary leave, the patient resumed his normal pitching routine finding that he was able to function completely nor- 
mally. When he was re-examined nine months later, he did not complain of any symptoms. Although some residual atrophy was still apparent, the strength of his infraspinatus was found to be normal.

\section{Electrodiagnostic findings}

Electrodiagnostic studies in all cases demonstrated isolated denervation in the infraspinatus consisting of fibrillation potentials, positive sharp waves and single unit recruitment of normal motor unit potentials (MUPs). Extensive electromyography (EMG) established no other abnormalities (and included examining the following muscles in all cases: supraspinatus, mid to low cervical paraspinal muscles, serratus anterior, deltoid, biceps brachii, triceps brachii, brachioradialis, flexor carpi radialis; and the following muscles in most cases: trapezius, rhomboids, extensor carpi radialis, flexor pollicis longus, first dorsal interosseous, abductor pollicis brevis). MUPs did not suggest myopathy (that is, lowamplitude, short duration MUPs were not present diffusely), and screening of peripheral nerves for a diffuse condition was negative.

The compound muscle action potentials (CMAPs) to the denervated infraspinatus muscles were also abnormal (standard procedures used $^{10}$ consisted of symmetrically placed surface electrodes to monitor the responses on Erb's point stimulation). In two cases surface electrodes were used and the CMAP amplitude was found to be significantly low in comparison with the asymptomatic side (38\% and $50 \%$ ), but the latency was normal and symmetrical $(2.8$ to $3.1 \mathrm{~ms})$. In the third case, needle electrode monitoring was used (precluding reliable measurement of the CMAP amplitude), but the latency was prolonged ( $14.8 \mathrm{~ms}$ compared with $3.2 \mathrm{~ms}$ on the asymptomatic side).

\section{Discussion}

These three patients were athletic males between the ages of 22 and 25 years. An isolated event (skeet shooting) preceded the onset in one. The other deficits developed insidiously with a shoulder ache occurring in one. In only one case was weakness demonstrated on careful manual muscle examination.

The clinical differential diagnosis of shoulder weakness (before the focality is demonstrated) includes the more common C5, C6 radiculopathy, a myopathy (such as polymyositis), a Parsonage-Turner syndrome (brachial plexitis), and rotator cuff injury. The latter two were unsupported by history. All but the last were unsupported by electrodiagnostic studies.

The lesion involved the innervation of the infraspinatus muscle only, consistent with a lesion at the SGN. These abnormalities were primarily axonal in two cases-denervation on EMG and low amplitude CMAP.

To examine for axonal pathology, EMG is the most sensitive test. In addition, the evoked CMAP amplitude provides an estimate of the degree of muscle atrophy. To estimate this, however, it is important to monitor the CMAP using a surface electrode, as a needle electrode records from a limited field. In addition, because of the variation in normal values (probably reflecting the range of the overlaying superficial muscle thickness in athletic shoulders), a normal control value would best be measured in the asymptomatic arm of the same patient.

In case 3 there is a prolonged latency which suggests a conduction abnormality. This can occur in a focal lesion of the myelin or in an axonal lesion during the early reparative stage (as may low amplitude MUPs) because of loss of the faster conducting fibres and regeneration of immature fibres which initially conduct more slowly. ${ }^{11}$

The key muscle to examine to distinguish between a lesion at the SSN and the SGN is the supraspinatus. If this is involved, the lesion cannot be at the SGN. Sparing of the supraspinatus, in contrast to marked infraspinatus involvement, places the lesion at the SGN.

We reviewed all the SGN cases, including the 10 that were previously reported. ${ }^{2-8}$ In all cases, there was a relationship with strenuous exercise. It occurred primarily in males between the ages of 18 and 41 , although the oldest patient was 79. Pain was not a major complaint in most cases. Weakness may not be a major feature, even on manual muscle testing. There was an insidious onset with the patient often unaware until an observer commented on the atrophy.

The absence of weakness deserves comment. It is possible that external rotation is omitted during the manual muscle examination. It is also possible, however, for a deficit to be compensated by synergistic muscles. A similar situation has been documented in cases of axillary nerve lesions where synergistic muscles have been seen to substitute effectively for atrophic deltoid muscles. ${ }^{12-14}$ Perhaps substitution is occurring here where the patients are all athletes in excellent physical condition.

The previously reported 31 cases of SSN lesions were reviewed., ${ }^{95-27}$ In 21 there was information indicating that the supraspinatus was also involved, placing the lesion at the $\mathrm{SSN}$. In ten cases, however, this was unclear ${ }^{9,15,22,25,26}$ as it is impossible to tell whether EMG examination was performed on the supraspinatus muscle. In one case, ironically, "the patient was referred for EMG evaluation of the right infraspinatus."26 Another patient reported in 1975 with external rotation weakness had a decompression of the SSN only and did not improve. ${ }^{9}$ This may well be a case of SGN entrapment. Thus before there was an awareness of the alternative localisation to the SGN, some of the reported cases of SSN lesions may have been erroneously localised. The true frequency of SGN lesions is probably higher than is apparent from the literature, as suggested by our experience.

We reviewed the characteristics of the 21 SSN cases with clear localisation only. Six of the patients were female. Thirteen of the patients were aged 16 to 41 , although the ages ranged to 70 . There was an association with hypertrophy of the suprascapular ligament, ${ }^{19}$ 
ganglion, ${ }^{21}$ systemic lupus erythematosus, ${ }^{25}$ and possibly rheumatoid arthritis. ${ }^{24}$ Many cases were related to shoulder trauma or heavy usage of the shoulder joint. A fracture of the scapula occurred in one case, ${ }^{18}$ and anterior shoulder dislocation in another. ${ }^{27}$ When adequate details were provided, shoulder pain was a major complaint, often with radiation.

SGN lesions usually followed chronic overusage of the shoulder. This included two weight-lifters, a baseball player, a fencing instructor, a racketball player, and a 79 year old woman who performed arm-pully exercises. (SGN lesions may also occur in top-level volleyball players, ${ }^{28}$ but more careful examination revealed supraspinatus abnormalities, placing the lesion at the $\mathrm{SSN}^{29}$ ). Relationship to more acute shoulder overusage occurred after long throws by a baseball outfielder, and in one patient after a single session of skeet-shooting. The onset of SGN lesions was more insidious than SSN lesions. In some, weakness was not a feature as a symptom or a sign. Focal infraspinatus atrophy was the major problem, and this was usually called to the patient's attention.

The major clinical distinction between SSN and SGN lesions, however, was the smaller role played by pain, whereas it was always the presenting complaint in SSN lesions (and in the even more common Parsonage-Turner syndrome). This is not surprising as the distal portion of the suprascapular nerve is a pure motor nerve. The only sensory branches separate proximal to the supraspinatus branch. ${ }^{30}$

The mechanism at each entrapment point may differ. Drez ${ }^{17}$ stressed that the nerve is fixed normally at its origin in the upper brachial plexus and at the SSN. In SSN lesions, the nerve may be tethered under an abnormal ligament or pinched by a narrowing at that point (due to fracture or tumour). Kopell and Thompson have demonstrated that certain shoulder movements (cross body adduction) stress the nerve at this point. ${ }^{1}$ Similar compression can occur in SGN lesions: there was surgical demonstration of a ganglionic cyst in two cases, ${ }^{2,8}$ and of a hypertrophic spinoglenoid ligament in another. ${ }^{3}$

Aiello et $a l^{\beta}$, however, described a more dynamic mechanism in SGN lesions. The spinoglenoid ligament, which inserts medially on the scapular spine, has a variable lateral insertion: although in some people it inserts on the lateral edge of the scapula, more significantly in others it inserts on the scapulohumeral joint capsule. In the latter case, movements of the arm will affect the diameter of the SGN and cause repeated focal compression of the nerve during exercise. It might also explain the occurrence of synovial cysts, which may be related to the joint capsule.

An alternative mechanism was suggested by Ferretti et al. ${ }^{28}$ In $30 \%$ of subjects, the nerve ends as three terminal branches instead of a plexus. ${ }^{31}$ The nerve in these subjects forms an acute angle as it curves around the scapular spine, where it is vulnerable to traction injury.

1 Kopell HP, Thompson WAL. Peripheral entrapment neuropathies. Baltimore: Williams and Wilkins, 1963:131-42.

2 Ganzhorn RW, Hocker JT, Horowitz M. Suprascapularnerve entrapment; a case report $J$ Bone Joint Surg $(\mathrm{Am})$ 1981;63A:492-4.

3 Aiello I, Serra G, Traina GC, Tugnochi V. Entrapment of the suprascapular nerve at the spinoglenoid notch. $A n n$ Neurol 1982;12:314-6.

4 Bryan WJ, Wild JJ Jr. Isolated infraspinatus atrophy. A common cause of posterior shoulder pain and weakness in throwing athletes? Am J Sports Med 1989;17:130-1.

5 Goodman CE. Unusual nerve injuries in recreational activities. Am J Sports Med 1983;11:224-7.

6 Jerosch J, Hille E, Schulitz KP. (Selective paralysis of the infraspinatus muscle, caused by compression of the infraspinatus branch of the supraspinatus muscle). Sporspinatus branch of the supraspin
tverletz Sportschaden 1987;1:231-3.

7 Lang C, Druschky KF, Sturm U, Neundorfer B, Fahlbusch R. (Suprascapular nerve entrapment syndrome). Dtsch Med Wochenschr 1988;113:1349-53.

8 Thompson RC Jr, Schneider W, Kennedy T. Entrapment neuropathy of the inferior branch of the suprascapular nerve by ganglia. Clin Orthop 1982;166:185-7.

9 Clein LJ. Suprascapular entrapment neuropathy. $J$ Neurosurg 1975;42:337-42.

$10 \mathrm{Ma} \mathrm{DM}$, Liveson JA. Nerve conduction handbook. Philadelphia: FA Davis, 1983:54-6.

11 Brown WF. The place of electromyography in the analysis of traumatic peripheral nerve lesion. In: Brown WF, Bolton $\mathrm{CF}$, eds. Boston: Clinical electromyography. Butterworths, 1987:163-4.

12 Babcock JL, Wray JB. Analysis of abduction in a shoulder with deltoid paralysis due to axillary nerve injury. Clin Orthop 1970;68:116-20.

13 Staples OS, Watkins AL. Full active abduction in traumatic paralysis of the deltoid. J Bone Joint Surg 1943;25:85-9.

14 Wynn Parry CB. Shoulder abduction with deltoid paralysis. Ann Phys Med 1954;2:178-9.

15 Augustin P, Verdure L, Samson M. Le syndrome du nerf suscapulaire a l'Etroit; une neuropathie canalaire souvent méconnue. Rev Neurol (Paris) 1976;132:219-22.

16 Cracchiola A 3rd, Marmor L. Peripheral entrapment neuropathies. JAMA 1968;204:431-4.

17 Drez D Jr. Suprascapular neuropathy in the differential diagnosis of rotator cuff injuries. Am J Sports Med 1976;4:43-5.

18 Edeland HG, Zachrisson BE. Fracture of the scapular notch associated with lesion of the suprascapular nerve. Acta associated with lesion of the
Orthop $S$ cand 1975;46:758-63.

19 Garcia G, McQueen D. Bilateral suprascapular-nerve entrapment syndrome; case report and review of the literature. J Bone Joint Surg (Am) 1981;63A:491-2.

20 Gelmers HJ, Buys DA. Suprascapular entrapment neuropathy. Acta Neurochir (Wien) 1977;38:121-4.

21 Hirayama T, Takemitsu Y. Compression of the suprascapular nerve by a ganglion at the suprascapular notch Clin Orthop 1981;155:95-6.

22 Kaplan PE, Kernahan WT Jr. Rotator cuff rupture: management with suprascapular neuropathy. Arch Phys Med Rehabil 1984;65:273-5.

23 Rask MR. Suprascapular nerve entrapment; a report of two cases treated with suprascapular notch resection. Clin Orthop 1977;123:73-5.

24 Rask MR. Suprascapular axonotmesis and rheumatoid arthritis; report of a case treated conservatively. Clin Orthop ritis; report of a

25 Sarno JB. Suprascapular nerve entrapment. Surg Neurol 983;20:493-7.

26 Steiman I. Painless infraspinatus atrophy due to suprascapular nerve entrapment. Arch Phys Med Rehabil 1988;69:641-4.

27 Zoltan JD. Injury to the suprascapular nerve associated with anterior dislocation of the shoulder: case report and review of the literature. J Trauma 1979;19:203-6.

28 Ferretti A, Cerullo G, Russo G. Suprascapular neuropathy in volleyball players. J Bone Joint Surg (Am) 1987;69A:260-3.

29 Holzgraefe M, Klingelhofer J, Eggert S, Benecke $R$ (Chronic neuropathy of the suprascapular nerve in high performance athletes). Nervenarzt 1988;59:545-8.

30 Horiguchi $M$. The cutaneous branch of some human suprascapular nerves. J Anat 1980;130:191-5.

31 Mestagh H, Drizenko A, Ghestem PH. Anatomical bases of suprascapular nerve syndrome. Anat Clin 1981;3:67-71.
sugh 1 , Drizenko A, Ghestem PH. Anatomical bases of 